\title{
Pulmonary haemodynamics after single-lung transplantation for end-stage pulmonary parenchymal disease
}

\author{
Ø. Bjørtuft*, S. Simonsen**, O.R. Geiran+, J.G. Fjeld++, E. Skovlund\#, J. Boe*
}

\begin{abstract}
Pulmonary haemodynamics after single-lung transplantation for end-stage pulmonary parenchymal disease. Ø. Bjørtuft, S. Simonsen, O.R. Geiran, J.G. Fjeld, E. Skovlund, J. Boe. (C) ERS Journals Ltd 1996.

ABSTRACT: In a prospective study, we investigated the effect of single-lung transplantation (SLT) on pulmonary haemodynamics and the relationship between pulmonary hypertension (PH) and the fraction of perfusion to the transplant in patients with end-stage pulmonary parenchymal disease.

Twenty four SLT recipients were included in the study, 19 with chronic obstructive pulmonary disease (COPD), two with sarcoidosis and three with fibrosing alveolitis. Spirometry, determination of arterial blood gas values, perfusion scintigraphy and right heart catheterization were performed before and 1, 6, 12 and 24 months after transplantation. Patients with a mean pulmonary artery pressure $\left(\bar{P}_{\text {pa }}\right) \geq 20 \mathrm{mmHg}$ before transplantation were defined as having PH (PH group, 15 patients) and the remainder ( 9 patients) constituted the non-PH group.

In the PH group, $\bar{P}$ pa and pulmonary vascular resistance (PVR) were significantly decreased after transplantation: $28 \pm 2$ to $18 \pm 1 \mathrm{mmHg}$ and 288 to $161 \pm 11$ dyne $\cdot \mathrm{s}^{-1} \cdot \mathrm{cm}^{-5}$, respectively $($ mean \pm SEM). In the non-PH group, the haemodynamic parameters were unchanged after transplantation. Over the 2 year follow-up period, no significant change was found in $\bar{P}_{\text {pa }}$ and PVR, nor any difference between the PH and non-PH group. There was no significant difference between the two groups in terms of pulmonary perfusion to the graft.

In conclusion, patients with pulmonary hypertension obtain pulmonary haemodynamics within the normal range after single-lung transplantation. Presence or absence of pulmonary hypertension before transplantation does not influence perfusion to the graft. These findings persist up to $2 \mathrm{yrs}$, despite the coexistence of an "end-stage" native lung and a lung transplant.

Eur Respir J., 1996, 9, 2007-2011.
\end{abstract}

\author{
Depts of *Thoracic Medicine, **Cardiology, \\ ${ }^{+}$Cardiothoracic Surgery, and ${ }^{++}$Nuclear Medi- \\ cine, Rikshospitalet, University Hospital, \\ Oslo, Norway. \#Section of Medical Statistics, \\ University of Oslo, Norway.
}

Correspondence: $\varnothing$. Bjørtuft Lungeavdelingen

Rikshospitalet

0027 Oslo

Norway

Keywords: Lung transplantation pulmonary haemodynamics

pulmonary parenchymal disease pulmonary perfusion

Received: October 291995 Accepted after revision June 281996
In patients with end-stage pulmonary parenchymal disease, single-lung transplantation (SLT) is established as a treatment with acceptable survival [1], and satisfactory medium term pulmonary function $[2,3]$.

End-stage pulmonary parenchymal diseases are associated with increased pulmonary artery pressure $(P \mathrm{pa})$ in the majority of patients [4-6]. In these patients, SLT improves pulmonary haemodynamic abnormalities in the early postoperative period [7, 8], but scarce data are available during follow-up in patients with moderately increased $P$ pa [9]. On the other hand, in patients with primary pulmonary hypertension $(\mathrm{PH})$ and other causes of severe PH, SLT has recently been associated with normalized pulmonary haemodynamics persisting for 4 yrs [10]. The impact of PH on survival and functional status in SLT is, however, controversial [8, 10].

After SLT for pulmonary parenchymal disease, the mean fraction of perfusion to the transplanted lung is $70-80 \%$, but with individual values ranging $50-95 \%$ $[2,3,11,12]$. The relationship between PH before transplantation and the fraction of perfusion to the allograft has not previously been studied.

We have, therefore, conducted a prospective study to evaluate the effect of SLT on pulmonary haemodynamics in patients with pulmonary parenchymal disease. The investigations were performed during a 2 year follow-up period after transplantation, and include the relationship between $\mathrm{PH}$ and the relative perfusion to the transplant.

\section{Patients and methods}

Between March 1990 and March 1994, 27 patients with end-stage pulmonary parenchymal disease underwent single-lung transplantation. The operative technique, immunosuppression and follow-up have been described previously $[13,14]$. Three patients died early postoperatively. The diagnosis, functional characteristics before transplantation and causes of death are summarized in table 1. No follow-up assessments are available in these patients and, as a result, they have not been included in the study. The 24 survivors (mean age 50 yrs, range 40-60 yrs) with a mean observation time after transplantation of 30 months (range 13-61 months) are the basis of this report. Demographic data are shown in table 2 . 
Table 1. - Clinical characteristics of the three patients who died early postoperatively

\begin{tabular}{|c|c|c|c|c|c|}
\hline $\begin{array}{l}\text { TX } \\
\text { No. }\end{array}$ & Diagnosis & $\begin{array}{c}\text { Age } \\
\text { yrs }\end{array}$ & $\begin{array}{c}\bar{P}_{\mathrm{pa}^{\dagger}} \\
\mathrm{mmHg}\end{array}$ & Cause of death & $\begin{array}{c}\text { Time after TX } \\
\text { weeks }\end{array}$ \\
\hline 4 & Sarcoidosis & 53 & 60 & Pneumonia, ARDS & 1 \\
\hline 20 & Chronic thromboembolic $\mathrm{PH}$ & 33 & 48 & CMV pneumonitis & 6 \\
\hline 24 & FA & 64 & 44 & Coronary ischaemia & 2 \\
\hline
\end{tabular}

TX: treatment (transplantation); $\bar{P}_{\mathrm{pa}^{\dagger}}$ : pre-operative mean pulmonary artery pressure; ARDS: adult respiratory distress syndrome; PH: pulmonary hypertension; CMV: cytomegalovirus; FA: fibrosing alveolitis.

Table 2. - Demographics of the 24 surviving singlelung transplanted patients

\begin{tabular}{lc}
\hline & Pts \\
& $\mathrm{n}$ \\
\hline Sex & \\
$\quad$ Male/Female & $13 / 11$ \\
Aetiology & \\
$\quad$ COPD & 19 \\
$\quad$ FA & 3 \\
$\quad$ Sarcoidosis & 2 \\
Transplantation & \\
$\quad$ Right/left lung & $13 / 11$ \\
\hline
\end{tabular}

Pts: patients; COPD: chronic obstructive pulmonary disease; FA: fibrosing alveolitis.

The pretransplant assessment included spirometry, determination of arterial blood gas values, pulmonary perfusion scintigraphy and right heart catheterization. After transplantation, the same tests were repeated after 1, 6, 12 and 24 months. In the late follow-up period, six recipients died. The causes of death were: acute pancreatitis (patient No. 3, 58 months after transplantation); malignant melanoma (patient No. 8, 8 months); obliterative bronchiolitis (patient No. 9, 14 months); bronchial stenosis (patient No. 16, 9 months); obliterative bronchiolitis and intra-abdominal bleeding after liver biopsy (patient No. 19, 10 months); and massive haemoptysis (patient No. 26, 2 months). Three patients were retransplanted on the contralateral side because of bronchiolitis obliterans syndrome [15] 11, 19 and 39 months after the first transplantation, and were excluded from further follow-up. The number of patients at the different follow-up times are, thus, as follows: before and 1 month after transplantation, 24 patients; after 6 months, 19 patients; after 1 year, 18 patients; and after 2 yrs, 10 patients ( 7 patients had an observation time of between 12 and 24 months, leaving 10 with a 24 month followup).

Patients with a mean pulmonary artery pressure $\left(\bar{P}_{\mathrm{pa}}\right)$ of $\geq 20 \mathrm{mmHg}$ before transplantation were defined as having pulmonary hypertension [16], constituting the PH group. Patients with a $\bar{P}$ pa of $<20 \mathrm{mmHg}$ were defined as the non-PH group.

\section{Right heart catheterization}

After fasting overnight, a standard right heart catheterization was performed in the supine position without premedication. A 7F Cournand catheter was advanced from a femoral vein to the pulmonary artery. Pressures were measured with SensoNor 840 transducers (SensoNor, Horten, Norway) using a Mingograph 7 ink jet recorder (Siemens-Elema, Solna, Sweden) with zero reference level in the fourth intercostal space in the anterior axillary line. Cardiac output (CO) and oxygen uptake $\left(V^{\prime} \mathrm{O}_{2}\right)$ were measured using the Fick principle. The haemodynamic recordings were $\bar{P}_{\mathrm{pa}}$ (mean, systolic and diastolic), pulmonary capillary mean wedge pressure $(P$ pcw $)$, right atrial mean pressure $(P$ ra $)$ and pulmonary vascular resistance (PVR). PVR was calculated as $(\bar{P}$ pa $-P$ pcw $) \cdot 80 / \mathrm{CO}$. Cardiac index (CI) is $\mathrm{CO} \cdot \mathrm{m}^{-2}$ body surface.

\section{Pulmonary function tests}

Dynamic lung volumes were measured using an automated pulmonary function unit (Gould 2400; Sensormedics, Bilthoven, The Netherlands). At least three satisfactory trials were performed. The highest forced vital capacity (FVC) and forced expiratory volume in one second (FEV1) were recorded.

Arterial blood samples were obtained for measurements of arterial oxygen tension $\left(\mathrm{Pa}_{\mathrm{a}} \mathrm{CO}_{2}\right)$ and arterial carbon dioxide tension $\left(\mathrm{Pa}_{\mathrm{a}}, \mathrm{CO}_{2}\right)$, with the patients resting and breathing room air.

\section{Quantitative perfusion scintigraphy}

Macroaggregated albumin (IFE MAA; Institutt for Energiteknikk, Norway) was labelled with $99 \mathrm{~m} T \mathrm{c}$ and an intravenous dose of $180 \mathrm{MBq}$ in approximately $1 \mathrm{~mL}$ was administered during $1 \mathrm{~min}$, with the patient in the supine position, breathing in and out slowly and deeply. With the camera in the dorsal position, the imaging was started immediately after the injection, and continued until a picture with 500,000 counts was obtained. Thereafter, using the same acquisition time as in the dorsal view, scintigrams from the anterior and from the four oblique views were taken. The perfusion of each lung was expressed as a percentage of the total counts in both lungs, using the arithmetric mean of the counts in the anterior and posterior view.

\section{Statistical analysis}

A mixed model analysis of variance (ANOVA) [17] with repeated measurements was used to analyse the data. In the tables, the results are presented as estimated mean ISEM in each group before transplantation and after 
Table 3. - Individual mean pulmonary artery pressure $\left(\bar{P}_{p a}\right)$ values before and after transplantation

\begin{tabular}{|c|c|c|c|c|c|c|}
\hline \multirow{2}{*}{$\begin{array}{l}\text { TX } \\
\text { No. }\end{array}$} & \multirow{2}{*}{ Diagnosis } & \multicolumn{5}{|c|}{$\bar{P}_{\text {pa }} \mathrm{mmHg}$} \\
\hline & & Before & $1 \mathrm{mo}$ & $6 \mathrm{mo}$ & $12 \mathrm{mo}$ & $24 \mathrm{mo}$ \\
\hline \multicolumn{7}{|c|}{ Patients with normal $\overline{\boldsymbol{P}}_{\text {pa }}$ before transplantation } \\
\hline 8 & COPD & 16 & 18 & - & Death $11 \mathrm{mo}$ & \\
\hline 10 & COPD & 14 & 13 & 18 & 14 & 15 \\
\hline 12 & COPD & 17 & 10 & 10 & 12 & 8 \\
\hline 15 & COPD & 18 & 22 & 22 & 28 & \\
\hline 16 & FA & 16 & 16 & 15 & Death & \\
\hline 18 & COPD & 16 & 14 & 10 & 13 & \\
\hline 21 & FA & 11 & 18 & 16 & 20 & \\
\hline 23 & COPD & 17 & 16 & 10 & 25 & \\
\hline 26 & COPD & 19 & 14 & Death & & \\
\hline \multicolumn{7}{|c|}{ Patients with PH before transplantation } \\
\hline 1 & Sarcoidosis & 36 & 26 & 22 & 33 & 24 \\
\hline 2 & COPD & 22 & 13 & 13 & - & 16 \\
\hline 3 & COPD & 24 & 9 & 12 & 13 & 16 \\
\hline 5 & COPD & 22 & - & 17 & 18 & 20 \\
\hline 6 & COPD & 45 & - & 30 & 25 & 19 \\
\hline 7 & Sarcoidosis & 36 & 28 & - & Re-TX $11 \mathrm{mo}$ & \\
\hline 9 & COPD & 29 & 14 & 17 & - & Death $14 \mathrm{mc}$ \\
\hline 11 & COPD & 29 & 16 & 18 & 22 & 19 \\
\hline 13 & COPD & 20 & 14 & 19 & 17 & 14 \\
\hline 14 & COPD & 24 & 12 & 16 & 17 & 16 \\
\hline 17 & COPD & 30 & 21 & 24 & 18 & Re-TX \\
\hline 19 & COPD & 25 & 12 & 20 & Death & \\
\hline 22 & FA & 28 & 14 & 21 & 18 & \\
\hline 25 & COPD & 22 & 16 & 14 & 18 & \\
\hline 27 & COPD & 30 & 21 & 21 & 16 & \\
\hline
\end{tabular}

TX: treatment (transplantation); -: missing value; Re-TX: retransplanted; COPD: chronic obstructive pulmonary disease; FA: fibrosing alveolitis; PH: pulmonary hypertension.

transplantation (corrected for time). A two-sample t-test was used to compare the values before transplantation between the $\mathrm{PH}$ and non-PH group. A p-value for the difference between groups is given. All the tests are two-sided, and a p-value of less than 0.05 is regarded as statistically significant.

\section{Results}

Fifteen patients (12 with chronic obstructive pulmonary disease (COPD), two with sarcoidosis, and one with fibrosing alveolitis (FA)) had $\mathrm{PH}$ before transplantation and constituted the $\mathrm{PH}$ group, while nine patients (seven with COPD and two with FA) made up the non-PH group (table 3 ). All of the individual $\bar{P}$ pa values in the observation period are presented in table 3 . Ten patients were followed for $2 \mathrm{yrs}$, and at 24 months they had a $\bar{P}$ pa of $17 \pm 1 \mathrm{mmHg}$.

Pulmonary haemodynamics in the $\mathrm{PH}$ and non-PH group before and after transplantation at 1, 6 and 12 months are presented in table 4.

$\bar{P}_{\mathrm{pa}}$ and PVR were significantly greater in the $\mathrm{PH}$ group compared to non-PH group before transplantation (table 5). The $\mathrm{Pa}_{\mathrm{a}} \mathrm{O}_{2}$ was lower in the $\mathrm{PH}$ group $(\mathrm{p}<0.05)$, while FVC, FEV1, and $P \mathrm{a}, \mathrm{CO}_{2}$ were not significantly different between the two groups (table 5).

After transplantation $\bar{P}_{\mathrm{pa}}$ and PVR were significantly decreased in the $\mathrm{PH}$ group (table 5).

Using the mixed model ANOVA and including all
Table 4. - Pulmonary haemodynamics in patients with pulmonary hypertension $(\mathrm{PH})$ and without (non- $\mathrm{PH})$, before and after transplantation

\begin{tabular}{|c|c|c|c|c|}
\hline & Before & $\begin{array}{c}1 \\
\text { month }\end{array}$ & $\begin{array}{c}6 \\
\text { months }\end{array}$ & $\begin{array}{c}12 \\
\text { months }\end{array}$ \\
\hline \multicolumn{5}{|l|}{ Non-PH group } \\
\hline Pts $\mathrm{n}$ & 9 & 9 & 7 & 6 \\
\hline $\bar{P}_{\text {ra }} \mathrm{mmHg}$ & $1 \pm 1$ & $0 \pm 1$ & $1 \pm 1$ & $2 \pm 0$ \\
\hline$P$ pa,syst $\mathrm{mmHg}$ & $24 \pm 1$ & $27 \pm 2$ & $24 \pm 3$ & $32 \pm 5$ \\
\hline Ppa,diast $\mathrm{mmHg}$ & $10 \pm 1$ & $9 \pm 1$ & $8 \pm 1$ & $11 \pm 2$ \\
\hline$\vec{P}_{\text {pa }} \mathrm{mmHg}$ & $16 \pm 1$ & $16 \pm 1$ & $14 \pm 2$ & $19 \pm 3$ \\
\hline $\bar{P}_{\text {pcw }} \mathrm{mmHg}$ & $6 \pm 1$ & $7 \pm 1$ & $6 \pm 1$ & $10 \pm 1$ \\
\hline PVR dynes $\cdot \mathrm{s}^{-1} \cdot \mathrm{cm}^{-}$ & $5177 \pm 28$ & $105 \pm 10$ & $145 \pm 22$ & $136 \pm 27$ \\
\hline $\mathrm{CI} \quad \mathrm{L} \cdot \mathrm{min}^{-1} \cdot \mathrm{m}^{-2}$ & $2.7 \pm 0.2$ & $3.4 \pm 0.3$ & $3.0 \pm 0.2$ & $3.1 \pm 0.33$ \\
\hline$V^{\prime} \mathrm{O}_{2} \quad \mathrm{~mL} \cdot \mathrm{min}^{-1}$ & $228 \pm 16$ & $237 \pm 13$ & $244 \pm 15$ & $232 \pm 18$ \\
\hline \multicolumn{5}{|l|}{ PH group } \\
\hline Pts $\mathrm{n}$ & 15 & 15 & 14 & 12 \\
\hline $\bar{P}_{\text {ra }} \mathrm{mmHg}$ & $5 \pm 1$ & $1 \pm 1$ & $3 \pm 1$ & $3 \pm 1$ \\
\hline$P$ pa,syst $\mathrm{mmHg}$ & $40 \pm 3$ & $27 \pm 2$ & $30 \pm 2$ & $30 \pm 1$ \\
\hline Ppa,diast $\mathrm{mmHg}$ & $18 \pm 2$ & $11 \pm 1$ & $11 \pm 1$ & $11 \pm 1$ \\
\hline$\vec{P}_{\text {pa }} \mathrm{mmHg}$ & $28 \pm 2$ & $17 \pm 2$ & $19 \pm 1$ & $20 \pm 1$ \\
\hline $\bar{P}$ pcw $\mathrm{mmHg}$ & $10 \pm 2$ & $6 \pm 1$ & $10 \pm 1$ & $9 \pm 1$ \\
\hline PVR dynes $\cdot \mathrm{s}^{-1} \cdot \mathrm{cm}^{-}$ & $5288 \pm 30$ & $149 \pm 11$ & $142 \pm 17$ & $163 \pm 19$ \\
\hline $\mathrm{CI} \mathrm{L} \cdot \mathrm{min}^{-1} \cdot \mathrm{m}^{-2}$ & $3.1 \pm 0.2$ & $3.4 \pm 0.2$ & $3.2 \pm 0.2$ & $3.0 \pm 0.2$ \\
\hline$V^{\prime} \mathrm{O}_{2} \quad \mathrm{~mL} \cdot \mathrm{min}^{-1}$ & $222 \pm 12$ & $208 \pm 11$ & $215 \pm 9$ & $201 \pm 7$ \\
\hline
\end{tabular}

Values are presented as mean \pm SEM. Pts: patients; $\bar{P}_{\text {ra: }}$ mean right atrial pressure; $P$ pa: pulmonary artery pressure; syst: systolic; diast: diastolic; $\bar{P}_{\text {pa: }}$ mean pulmonary artery pressure; $\bar{P}_{\text {pcw: }}$ mean pulmonary capillary wedge pressure; PVR: pulmonary vascular resistance; $\mathrm{CI}$ : cardiac index; $V^{\prime} \mathrm{O}_{2}$ : oxygen uptake. 
Table 5. - Arterial blood gas values, lung volumes, pulmonary vascular resistance, mean pulmonary artery pressure and perfusion to the transplanted side in patients with pulmonary hypertension $(\mathrm{PH})$ and without (non- $\mathrm{PH}$ ) before and after transplantation (estimated mean at 1, 6, 12 and 24 months)

\begin{tabular}{lcccc}
\hline & \multicolumn{2}{c}{ Before transplantation } & \multicolumn{2}{c}{ After transplantation } \\
& Non-PH & PH & Non-PH & PH \\
\hline${\mathrm{Pa}, \mathrm{O}_{2}}_{2} \mathrm{kPa}$ & $7.8 \pm 0.5$ & $6.8 \pm 0.2^{*}$ & $10.6 \pm 0.6$ & $9.9 \pm 0.4$ \\
$\mathrm{~Pa}, \mathrm{CO}_{2} \mathrm{kPa}$ & $6.1 \pm 0.5$ & $7.1 \pm 0.6$ & $5.0 \pm 0.2$ & $5.4 \pm 0.2$ \\
$\mathrm{FVC} \mathrm{L}$ & $2.18 \pm 0.40$ & $1.64 \pm 0.18$ & $2.84 \pm 0.24$ & $2.32 \pm 0.40$ \\
$\mathrm{FEV} 1 \mathrm{~L}$ & $0.82 \pm 0.15$ & $0.71 \pm 0.17$ & $1.52 \pm 0.14$ & $1.40 \pm 0.11$ \\
$\mathrm{PVR} \mathrm{dynes} \cdot \mathrm{s}^{-1} \cdot \mathrm{cm}^{-5}$ & $177 \pm 26$ & $288 \pm 32^{*}$ & $130 \pm 14$ & $161 \pm 11^{+}$ \\
$\bar{P}_{\mathrm{pa} \mathrm{mmHg}}$ & $16 \pm 1$ & $28 \pm 2^{* *}$ & $16 \pm 1$ & $18 \pm 1^{+}$ \\
Perfusion \% & $48 \pm 5$ & $48 \pm 2$ & $69 \pm 3$ & $76 \pm 2$ \\
\hline
\end{tabular}

Values are presented as mean \pm SEM in each group before transplantation, estimated mean values \pm SEM (measurements at 1, 6, 12 and 24 months) after transplantation (mixed model ANOVA with repeated measurements) and the p-values for comparison between the two groups. $\mathrm{Pa}, \mathrm{O}_{2}$ : arterial oxygen tension; $\mathrm{Pa}_{\mathrm{a}} \mathrm{CO}_{2}$ : arterial carbon dioxide tension; FVC: forced vital capacity; FEV1: forced expiratory volume in one second; $\bar{P}_{\text {pa: }}$ mean pulmonary artery pressure; PVR: pulmonary vascular resistance. Perfusion: perfusion to side of transplantation as a percentage of total perfusion; ANOVA: analysis of variance. ${ }^{*}, * *: \mathrm{p}<0.05,<0.01 \mathrm{vs}$ non-PH; ${ }^{+}: \mathrm{p}<0.05$ vs before transplantation.

the observations $(1,6,12$ and 24 months after transplantation), the pulmonary function, $\bar{P}$ pa, PVR and the perfusion to transplanted side in the two groups were analysed (table 5). There was no significant difference between the PH group and the non-PH group in any of these parameters, and there was no change during the observation period after the transplantation.

Figure 1 shows that half of the total perfusion before transplantation was directed to the lung that was replaced by the allograft. After transplantation, the percentage of total perfusion to the graft increased to approximately $70 \%$ both in the $\mathrm{PH}$ and non-PH group. The correlation between $\bar{P}_{\text {pa }}$ (dependent variable) and $P \mathrm{a}, \mathrm{O}_{2}$ and $\mathrm{FEV} 1$ was also analysed using the mixed model ANOVA with the inclusion of a covariate $\left(\mathrm{Pa}, \mathrm{O}_{2}\right.$ or FEV1). A significant correlation was found between $\bar{P}_{\mathrm{pa}}$ and $\mathrm{Pa}_{\mathrm{a}} \mathrm{O}_{2}(\mathrm{p}<0.001)$, with an estimated change in $\bar{P}_{\mathrm{pa}}=-1.69 \mathrm{mmHg}$ with a $1 \mathrm{kPa}$ increase in $\mathrm{Pa}, \mathrm{O}_{2}$. There was no correlation between $\bar{P}$ pa and FEV1 $(\mathrm{p}=0.91)$.

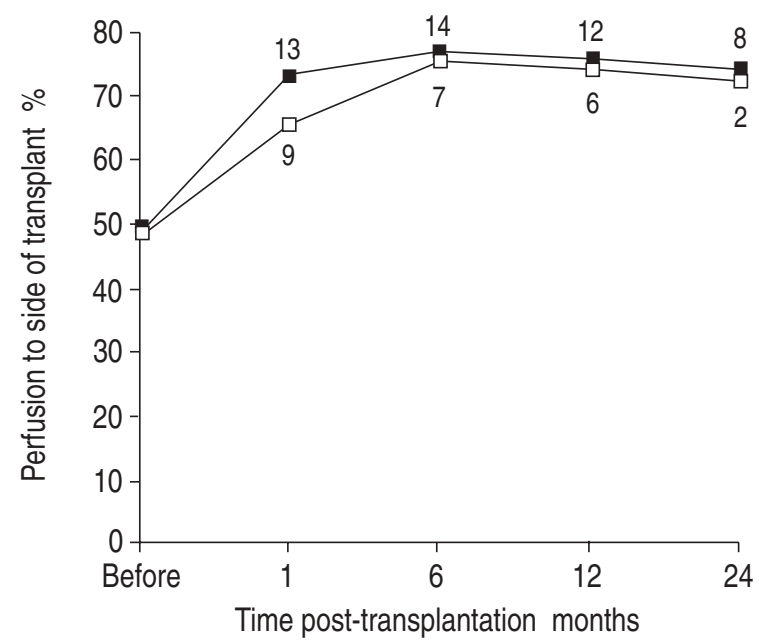

Fig. 1. - Percentage of total perfusion to the side of the transplant before and at different time intervals after transplantation. _ - : $\mathrm{PH}$ group, i.e. patients with a mean pulmonary artery pressure $\geq 20$ $\mathrm{mmHg}$ before transplantation; - $\square-$ : non-PH group, i.e. patients with mean pulmonary artery pressure $<20 \mathrm{mmHg}$ before transplantation. The number of patients in the two groups is indicated at the value points. PH: pulmonary hypertension.
There was no correlation between perfusion to the transplanted side (dependent variable) and $\bar{P}_{\text {pa }}$ and PVR $(\mathrm{p}=0.172$ and $\mathrm{p}=0.86$, respectively).

\section{Discussion}

In the present study, the patients with $\mathrm{PH}$ had mildto-moderately increased $\bar{P}$ pa values prior to transplant. Their pulmonary haemodynamics were within the normal range after SLT, and remained so after 2 yrs. The patient group with normal $\bar{P}_{\text {pa before transplantation had }}$ unchanged haemodynamics after transplantation. Furthermore, the percentage of pulmonary perfusion to the transplanted side was not significantly different in the two groups.

There are no previous reports of serial measurements of pulmonary haemodynamics after SLT for pulmonary parenchymal disease. In one report, however, with a single follow-up measurement in five patients with pulmonary fibrosis and $\mathrm{PH}$ (mean observation time 18 months, range 2-29 months), the $\bar{P}$ pa was $18 \mathrm{mmHg}$ [9], i.e. similar to the present results. In severe $\mathrm{PH}$ because of pulmonary vascular disease, SLT has become a feasible therapeutic option with normalized pulmonary haemodynamics and satisfactory functional improvement during follow-up [10, 18, 19]. These results persisted up to 4 yrs [10], and the haemodynamic results were similar to those in the present study. After 2 yrs (11 patients) and 4 yrs (6 patients) $\bar{P}$ pa was $21 \mathrm{mmHg}$, compared to a $\bar{P}$ pa of $17 \mathrm{mmHg}$ after 2 yrs (10 patients) in the present study. A normal $\bar{P}$ pa persisting for $2-4$ yrs after transplantation despite $\mathrm{PH}$ before transplantation indicates that a successful SLT is accompanied by normalized pulmonary haemodynamics in the longterm follow-up.

After SLT for severe pulmonary hypertension, there was a mismatch between ventilation and perfusion distributed to the transplant, approximately 50 and $80 \%$, respectively. Even with this mismatch, the functional status was satisfactory [10]. In the non-PH group in the present study, the lungs had only a slightly elevated PVR before transplantation and, theoretically, the opposite mismatch might appear; perfusion might be distributed evenly between the native and transplanted 
lungs, while ventilation would be directed mainly to the transplanted lung. However, the present study revealed a similar percentage of perfusion to the graft as in previous reports and, in addition, demonstrated that the perfusion to the transplanted lung was not significantly different between patients with and without PH before transplantation. Furthermore, this pattern persisted for at least 2 yrs.

Pulmonary artery pressure in pulmonary parenchymal disease has previously been shown to be inversely correlated with $\mathrm{Pa}_{\mathrm{a}, \mathrm{O}_{2}}[16,20-22]$. The correlation between FEV 1 and $\bar{P}$ pa is controversial; in one study, no correlation was found [23], whilst another long-term study reported a weak inverse correlation [16]. In the present study, in accordance with these results, a significant inverse correlation was found between $\mathrm{Pa}, \mathrm{O}_{2}$ and $\bar{P}$ pa, but no correlation between FEV 1 and $\bar{P}$ pa.

SLT is the most effective way of utilizing available donor organs. However, in one study a $\bar{P}$ pa greater than $30 \mathrm{mmHg}$ before transplantation was reported to be associated with lower 1 year survival, prolonged intensive care unit stay and less symptomatic improvement. Accordingly, the authors raised the question of whether SLT may be suboptimal therapy in patients with PH [8]. In another study of SLT for severe PH, the survival and functional results were good, but the $\mathrm{PH}$ patients were not compared with non-PH patients [10]. The three patients in the present study with early postoperative death had a $\bar{P}$ pa greater than $30 \mathrm{mmHg}$, but their causes of death are difficult to associate with $\mathrm{PH}$. The other six deaths had a $\bar{P}_{\text {pa }}$ below $30 \mathrm{mmHg}$, and three were in the $\mathrm{PH}$ and three the non-PH group. Some controversy, therefore, still exists about the impact of $\mathrm{PH}$ on the outcome of SLT. Further long-term studies of the effects of PH in SLT appear to be warranted.

In conclusion, the occurrence of mild-to-moderate pulmonary hypertension before transplantation is not associated with elevated pressures in the pulmonary circulation after transplantation and does not influence perfusion to the graft. The present findings indicate that the coexistence of a lung graft with normal function and an end-stage diseased native lung has no negative impact on the pulmonary haemodynamics in long-term follow-up.

\section{References}

1. Kaye MP. The registry of the International Society for Heart and Lung Transplantation: Eleventh official report - 1994. J Heart Lung Transplant 1994; 13: 561-570.

2. Grossmann RF, Frost A, Zamel N, et al., and the Toronto Lung Transplant Group. Results of single-lung transplantation for bilateral pulmonary fibrosis. $N \mathrm{Engl}$ J Med 1990; 322: 727-733.

3. Mal H, Sleiman C, Jebrak G, et al. Functional results of single-lung transplantation for chronic obstructive lung disease. Am J Respir Crit Care Med 1994; 149: 1476-1481.

4. Nocturnal Oxygen Therapy Trial Group. Continuous or nocturnal oxygen therapy in hypoxemic chronic obstructive lung disease: a clinical trial. Ann Intern Med 1980; 93: 391-398.

5. Medical Research Council Working Party. Long-term domiciliary oxygen therapy in chronic hypoxic cor pulmonale complicating chronic bronchitis and emphysema. Lancet 1981; 1: 681-686.
6. Hawrylkiewicz I, Izdebska-Makosa Z, Grebska E, et al. Pulmonary hemodynamics at rest and on exercise in patients with idiopathic pulmonary fibrosis. Bull Eur Physiopathol Respir 1982; 18: 403-410.

7. De Hoyos AL, Patterson GA, Maurer JR, et al. Pulmonary transplantation: early and late results. $J$ Thorac Cardiovasc Surg 1992; 103: 295-306.

8. Bando K, Keenan RJ, Paradis IL, et al. Impact of pulmonary hypertension on outcome after single-lung transplantation. Ann Thorac Surg 1994; 58: 1336-1342.

9. Doig JC, Corris PA, Hilton CJ, Dark JH, Bexton RS. Effect of single-lung transplantation on pulmonary hypertension in patients with end-stage fibrosing lung disease. Br Heart J 1991; 66: 431-434.

10. Pasque MK, Trulock EP, Cooper JD, et al. Single-lung transplantation for pulmonary hypertension: single institution experience in 34 patients. Circulation 1995; 92: 2252-2258.

11. Gibbons WJ, Levine SM, Bryan CL, et al. Cardiopulmonary exercise responses after single-lung transplantation for severe obstructive lung disease. Chest 1991; 100: 106-111.

12. Ross DJ, Waters PF, Waxman AD, Koerner SK, Mohsenifar QZ. Regional distribution of lung perfusion and ventilation at rest and during exercise after unilateral lung transplantation. Chest 1993; 104: 130-135.

13. Geiran O, Lindberg H, Bjørtuft $\varnothing$, et al. Single-lung transplantation: surgical experiences with the first seven patients. Scand J Thorac Cardiovasc Surg 1992; 26: 163-168.

14. Bjørtuft $\varnothing$, Johansen B, Boe J, Foerster A, Holter E, Geiran O. Daily home spirometry facilitates early detection of rejection in single-lung transplant recipients with emphysema. Eur Respir J 1993; 6: 705-708.

15. International Society for Heart and Lung Transplantation: Cooper JD, Billingham M, Egan T, et al. A working formulation for the standardization of nomenclature and for clinical staging of chronic dysfunction in lung allografts. J Heart Lung Transplant 1993; 12: 713-716.

16. Weitzenblum E, Sautegeau A, Ehrhart M, Mammosser M, Hirth C, Roegel E. Long-term course of pulmonary arterial pressure in chronic obstructive pulmonary disease. Am Rev Respir Dis 1984; 130: 993-998.

17. Dixon WJ (editor). BMDP statistical software manual. Vol. 2. Berkeley, UCLA Press, 1992.

18. Levine SM, Gibbons WJ, Bryan CL, et al. Single lung transplantation for primary pulmonary hypertension. Chest 1990; 98: 1107-1115.

19. Pasque MK, Trulock EP, Kaiser LR, Cooper JD. Singlelung transplantation for pulmonary hypertension: three month hemodynamic follow-up. Circulation 1991; 84: 2275-2279.

20. Weitzenblum E, Loiseau A, Hirth C, Mirhom R, Rasaholinjanahary J. Course of pulmonary hemodynamics in patients with chronic obstructive pulmonary disease. Chest 1979; 75: 656-662.

21. Cooper CB, Waterhouse J, Howard P. Twelve year clinical study of patients with hypoxic cor pulmonale given long-term domiciliary oxygen therapy. Thorax 1987; 42: 105-110.

22. Timms RM, Khaja FU, Williams GW, and the Nocturnal Oxygen Therapy Trial Group. Hemodynamic response to oxygen therapy in chronic obstructive pulmonary disease. Ann Intern Med 1985; 102: 29-36.

23. Weitzenblum E, Hirth C, Parini JP, Rasaholinjanahary J, Oudet P. Clinical, functional and pulmonary hemodynamic course of patients with chronic obstructive pulmonary disease followed-up over 3 years. Respiration 1978; 36: 1-9. 